\title{
PRIMERAS VALORACIONES ACERCA DE LOS EFECTOS DE LA REFORMA LABORAL DE 2012 EN MATERIA DE ESTRUCTURA DE LA NEGOCIACIÓN COLECTIVA EN ESPAÑA*
}

\section{FIRST REVIEWS ABOUT THE EFFECTS OF 2012 LABOR REFORM ON STRUCTURE OF COLLECTIVE BARGAINING IN SPAIN}

\author{
Jesús Cruz Villalón ${ }^{* *}$ \\ Universidad de Sevilla, España \\ Patrocinio Rodríguez Ramos ${ }^{* * *}$ \\ Universidad de Sevilla, España
}

\section{LOS PROBLEMAS DE LA MODIFICACIÓN DE LA ESTRUCTURA DE LA NEGOCIACIÓN COLECTIVA Y LOS OBJETIVOS PERSEGUIDOS CON SU REFORMA}

\subsection{La LENTA Y SUAVE ALTERACIÓN DE LA ESTRUCTURA DE LA NEGOCIACIÓN}

El análisis de la evolución y estado actual del modelo de negociación colectiva y su estructura, lejos de aparecer como una cuestión fácil y de comprensión certera, pasa por presentarse como una tema de enorme complejidad y afectado por múltiples factores y dispares elementos de confluencia.

Ha sido lugar común a la hora de analizar la estructura de la negociación colectiva y, en particular, cuando ello se efectúa en relación con nuestro sistema de relaciones laborales, afirmar que la misma se encontraba intensamente petrificada, de modo que en los momentos actuales

\footnotetext{
Este artículo recoge en su mayor parte las conclusiones obtenidas en un estudio realizado bajo la dirección del profesor Cruz Villalón, por encargo de la Comisión Consultiva Nacional de Convenios Colectivos del Ministerio de Empleo y Seguridad Social de España, sobre "La incidencia de la reforma de 2012 sobre la estructura de la negociación colectiva", en proceso de publicación. Además de los autores del artículo, participaron en ese estudio los profesores Rafael Gómez Gordillo y Carmen Ferradans Caramés.

** Catedrático de Derecho del Trabajo y de la Seguridad Social, Universidad de Sevilla.

... Profesora Titular de Derecho del Trabajo y de la Seguridad Social, Universidad de Sevilla. Contacto: patroci@us.es
} 
respondía a claves que se remontaban bien atrás en el tiempo. No cabe la menor duda de que factores históricos de muy diversa naturaleza en un momento dado perfilaron la constitución de una determinada unidad de negociación y la misma ha pervivido a lo largo de las décadas, tanto en lo que refiere a su ámbito de aplicación como incluso en lo que afecta a los contenidos de sus cláusulas, a pesar de los múltiples avatares que se han venido sucediendo en la evolución de nuestro sistema de relaciones laborales. Se trata de una realidad que difícilmente puede ser contradicha, pues diversos estudios de campo a estas alturas han logrado confirmar que importantes elementos de nuestra vigente estructura de la negociación colectiva sólo encuentran su respuesta acudiendo al modelo incipiente de las Bases de Trabajo de la Segunda República, a la división sectorial por actividades económicas predeterminadas por la autoridad laboral a través de las antiguas y ya derogadas plenamente Ordenanzas Laborales, así como a las unidades de negociación que se van constituyendo desde finales de los años ' 50 del siglo pasado a partir de la primera Ley de Convenios Colectivos Sindicales de 1958. Una vez constituida una determinada unidad negocial, por muy arbitraria y falta de fundamento que ésta sea en cuanto a la elección del ámbito de aplicación funcional y territorial, la misma se consolida, se pega cual ventosa al sistema de negociación colectiva en su conjunto, manifestando fortísimas resistencias a su desaparición o sustitución por una nueva unidad negocial; y ello, con independencia de las más o menos profundas transformaciones que se produzcan en el sistema productivo, en la estructura y conformación del poder político o sindical y en la propia voluntad declarada al menos expresamente por los protagonistas sindicales y empresariales de la negociación colectiva. Incluso a veces parece que nos instalamos en una perspectiva "gatopardiana", por cuanto que daría la impresión de que todos los proyectos diseñados por las grandes confederaciones sindicales y empresariales de racionalización de la estructura de la negociación colectiva acaban frenadas por un muro indestructible en el que se concentran todas las fuerzas conservadoras de resistencia al cambio.

Ahora bien, la anterior perspectiva, como todas aquellas radicales que pretenden una explicación simple, unitaria y absoluta de la realidad, acaban presentando una visión distorsionada del complejo mundo de las relaciones sociales, particularmente el relativo a las relaciones laborales. Tal apariencia de inmutabilidad puede deberse a una mirada miope en el corto período de la evolución de la negociación colectiva. Sin embargo, cuando las cosas se analizan en ciclos o fases temporales de mayor extensión y, sobre todo, se atiende no tanto a lo que permanece cuanto a lo que hay de novedoso, las valoraciones finales pueden experimentar matizaciones de superior alcance. La ya larga vigencia del Estatuto de los Trabajadores (ET) y, con ello, otros tantos de experiencia de negociación colectiva, unido al análisis de las más reciente reformas llevadas a cabo en materia de estructura de la negociación colectiva en 2012, pueden constituir una excelente excusa para efectuar un balance de lo sucedido en un período de tiempo suficientemente prolongado como para percibir mejor los fenómenos de transformación de la estructura de la negociación colectiva, que, por propia naturaleza, son lentos y progresivos.

$\mathrm{Y}$, desde esa perspectiva, en efecto, sin dejar de ser cierto que existen indudables resistencias a la alteración directa y desde dentro de las unidades de negociación que se han venido conformando a lo largo de las décadas precedentes, sin embargo, por vías indirectas y externas se ha estado produciendo una transformación cuantitativa y cualitativa de nuestra estructura negocial, contemplada ésta en su conjunto. Lo uno y lo otro no tiene necesariamente que ser contradictorio, pero sí tener una incidencia mutua y dialéctica. Probablemente lo que está sucediendo, a nuestro juicio, es que se produce un incremento de unidades negociales en clave aluvional; es decir, sin llegar a desaparecer prácticamente ninguna de las unidades negociales clásicas preexistentes, se incorporan a las mismas nuevos procesos negociales, que, en esos términos de acción indirecta y 
externa, pueden llegar a afectar a lo ya consolidado; y, en fase sucesiva, llegar a provocar incluso la marginación, cuando no la directa inanición, de las unidades negociales más antiguas. La hipótesis de trabajo, que pretendemos convertir al final de este estudio en conclusión, es que se produce cierta pervivencia de la estructura de siempre, como armazón básico de referencia, pero a la que se le van incorporando elementos de complemento ciertamente novedosos, que pueden llegar a estar incidiendo sobre el propio esqueleto de la estructura negocial ya establecida; probablemente en los últimos tiempos con mayor viveza y agilidad que en momentos precedentes. $O$ bien, si se quiere descrito en sentido inverso, que las transformaciones del sistema productivo y de las relaciones laborales o sociales, unido a la incidencia de las reformas de la legislación estatal particularmente de la correspondiente al año 2012, provocan la conformación de nuevas realidades, que en muchas ocasiones no son asimiladas o incorporadas dentro de los viejos niveles de negociación colectiva, desembocando en la creación de nuevas unidades de negociación; nuevas unidades que, de forma implícita, pueden acabar debilitando a los escenarios más clásicos de la negociación colectiva.

\subsection{UN DISEŃO LEGAL DE LA ESTRUCTURA COMPLEJO Y CON INSUFICIENCLAS}

En ese proceso evolutivo y de análisis un elemento central lo constituye el específico diseño normativo que se haya dado a la estructura y función de los diversos niveles negociales, así como el papel que la norma heterónoma y la convencional hayan tenido y tengan en tal configuración. Centrados en el examen de las sucesivas reformas legales que, desde la aparición del Estatuto de los Trabajadores en 1980, se han llevado a cabo en materia de modelo y estructura de la negociación colectiva, hay que destacar que aquéllas han terminado por dibujar un escenario jurídico particularmente complejo, preñado de específicas reglas acumuladas (en ocasiones fruto de un proceso de modificación aluvional, donde la nueva regla que se incorpora no termina por desbancar a la precedente), en ocasiones con cierto solapamiento aplicativo y donde es difícil a veces deslindar lo esencial de lo accesorio. Pero es que, además, esa complejidad y abundancia de reglas jurídicas no se ve justificada ni acompañada por el dato de abarcar y comprender toda o casi toda la gama posible de problemas aplicativos entre niveles de negociación, pues la realidad negocial en sede teórica resulta tan diversa que el esquema legal termina por presentar lagunas, determinadas imprecisiones técnicas o simplemente una respuesta legal que se aplica por exclusión sin que probablemente el legislador expresamente lo haya querido así; todo lo cual acaban dificultando la correcta interpretación y aplicación de la norma jurídica de rigor.

\subsection{Dificultades en El diagnóstico de la inCidenCia de los CAMbios legales}

Las modificaciones que de manera directa e indirecta han alterado las reglas que ordenan la estructura de la negociación colectiva no pueden considerarse menores, si bien los efectos que estas alteraciones están produciendo en el sistema de relaciones laborales español y, sobre todo, las que se producirán a medio plazo constituyen un espacio abonado para la proliferación de todo tipo de dudas y especulaciones, sobre el que se intentará arrojar algo de luz. De un lado, si el sistema de relaciones laborales instituye un edificio sustentado sobre un entramado normativo que articula y compensa los impulsos de fuerzas e intereses que apuntan hacia direcciones en no pocas ocasiones opuestas, la temporalmente reciente sucesión de cambios sobre distintos aspectos de la normativa laboral debe estar sin duda produciendo importantes efectos sobre el sistema de negociación colectiva y su estructura. Ahora bien, la tarea de concretar las consecuencias que se 
Jesús Cruz Villalón, Patrocinio Rodríguez Ramos / Primeras valoraciones acerca de los efectos de la reforma laboral de 2012 en materia de estructura de la negociación colectiva en España

producirán en el medio plazo y, sobre todo, la labor de individualizar las medidas a las que corresponde mayor responsabilidad en esta transformación constituyen objetivos que deben afrontarse con suma prudencia y haciendo uso de la mejor información disponible. A mayor abundamiento, tampoco resulta fácil diferenciar entre las transformaciones que traen causa directa de la deteriorada situación económica, y las que son inducidas por los cambios normativos; ni qué alteraciones poseen carácter coyuntural y, por ello, perderán protagonismo una vez se remonte la actual situación, y cuales otras poseen naturaleza estructural y, en consecuencia, se instalarán en nuestro sistema de manera definitiva.

\subsection{UN CONJUNTO VARIADO DE PREVISIONES Y DISPOSICIONES LEGALES}

En el estudio de la configuración legal de nuestro modelo y estructura de la negociación colectiva suelen citarse como preceptos clave los artículos 83 y 84 del Estatuto del los Trabajadores que, ubicados sistemáticamente en el título regulador de la negociación colectiva, regulan la materia relativa a las unidades de negociación y la concurrencia entre convenios colectivos. Pero hay que indicar de entrada que, al margen de que pueda centrarse el análisis en tales preceptos, la realidad normativa a tomar en consideración a la hora de realizar valoraciones sobre la estructura de nuestra negociación colectiva es mucho más amplia, variada y compleja. Para aprehender y comprender esta temática hemos de tomar en consideración no sólo otros preceptos del propio título III del Estatuto de los Trabajadores (reglas de legitimación negocial, eficacia de los convenios y su inaplicación, contenido mínimo....) sino disposiciones contenidas a lo largo de toda la norma. Así pues, junto a las reglas específicas que ordenan el sistema de articulación y concurrencia de convenios colectivos, aparecen, sin una adecuada sistemática, una pléyade de disposiciones y previsiones que, aunque sólo de forma muy laxa puedan considerarse incluidas en el concepto de la estructura de la negociación colectiva, no obstante, en la realidad práctica, no cabe duda de que tienen una notable influencia sobre ella. Pensemos en todo lo relativo al régimen jurídico de los acuerdos de empresa que, con funciones y cometidos específicos diseminados a lo largo del título I del Estatuto vienen a cumplir un concreto papel en la regulación general de la relación laboral; o las remisiones legales al papel de complemento de la negociación colectiva que, en ocasiones, lejos de ser aséptica, se inclina por dar preferencia a un determinado nivel de negociación. Así, no debe pasar inadvertido que esas remisiones al papel de complemento ( $y$ de incremento de flexibilidad vía convenio colectivo) fueron incorporándose a nuestro ordenamiento a través de sucesivas reformas, concertadas muchas de ellas, en las que los agentes sociales venían a aceptar la posible ampliación convencional de la flexibilidad derivada de la norma legal en tanto eran ellos quienes, vía convenio sectorial estatal $o$, en su defecto, de ámbito inferior, gobernarían el alcance de la medida (así acontece en lo relativo a la determinación de los puestos de trabajo, grupos, niveles o categorías profesionales objeto del contrato en prácticas y su duración -artículo 11.1 a) y b) ET-, o respecto a la duración máxima del contrato eventual -artículo 15.1 b) ET-, o de la ampliación de la duración del contrato para obra o servicio determinado -artículo 15.1 a) ET). Pues bien, las últimas reformas no recogen remisiones novedosas en materia de complemento regulador de la negociación colectiva, y cuando las han incorporado ha sido para ir omitiendo ese tipo de reglas de preferencia a favor del convenio sectorial por otras en las que, de forma general, se alude al convenio colectivo con clara vocación de incorporar el nivel de empresa a esa labor de adaptación y desarrollo del precepto legal (especialmente ilustrativo a este respecto resultan los últimas modificaciones en materia del trabajo a tiempo parcial y sus llamadas a la negociación 
colectiva -artículo 12.4 a), b), e) y f) ET); o la influencia indirecta que sobre la estructura y esqueleto de la negociación colectiva pueden tener los mecanismos de descuelgue e inaplicación de condiciones de trabajo; o el singular juego de un principio como el de norma más favorable que, inserto en el artículo 3.3 del Estatuto de los Trabajadores como mecanismo de solución global de conflictos entre normas estatales y paccionadas, puede tener una incidencia particular en la solución de eventuales concurrencias conflictivas entre convenios de distinto ámbito negocial; o, en fin, la importancia real de los convenios extraestatutarios que, justamente por ser tales, escapan a la reglas articuladoras y de afectación del Estatuto de los Trabajadores, por lo que no siempre es fácil determinar cómo juegan en relación a los convenios estatutarios ni tampoco cómo inciden sobre ellos reglas de modificación, adaptación y flexibilización interna de condiciones de trabajo como las contenidas en el artículo 41 del Estatuto de los Trabajadores en materia de modificación sustancial de condiciones de trabajo.

\subsection{COINCIDENCIA EN LOS RASGOS GENERALES DEL MODELO PREVIO A LA REFORMA DE 2012}

Antes de pasar al análisis concreto de las modificaciones llevadas a cabo por la reforma de 2012, y valorar sus efectos, tal vez sea conveniente realizar algunas consideraciones acerca de los rasgos generales del modelo y estructura negocial imperante antes de su entrada en vigor y de los medios e instrumentos más adecuados para llevar a cabo eventuales cambios estructurales.

La reforma de 2012 viene precedida de una general coincidencia en la conveniencia del cambio del modelo de negociación, y una cierta unanimidad en el diagnóstico de los principales problemas y disfunciones que lo aquejaban, léase, atomización de niveles negociales, con fuerte descoordinación y desarticulación entre ellos, fruto de un sistema que se adjetiva como heredero del franquismo y notablemente continuista. Aunque no de forma absoluta en atención a ese proceso de cierta transformación que venimos indicando (o al menos de intentos de alteración), lo cierto es que el sistema de negociación colectiva ha venido manifestado una fuerte naturaleza refractaria al cambio, de lo que no deja de ser elocuente que se haya resaltado cómo estudios y análisis sobre la materia realizados con más de treinta años de diferencia hayan puesto de manifiesto que poco había cambiado en lo que a este cuestión concernía.

\subsection{FACTORES QUE CONDICIONAN EL MODELO DE NEGOCIACIÓN}

En la explicación de esa cierta resistencia de la estructura negocial a cambios y alteraciones probablemente hayan de conjugarse factores muy diversos, tanto de carácter jurídico como extrajurídicos, algunos que afectan en similar medida a la efectividad de alteraciones en otras figuras e instituciones laborales, pero no parece desacertado conectar esa señalada lenta capacidad de transformación con la afirmada "consustancialidad" de la estructura de nuestra negociación colectiva con la realidad de nuestras relaciones laborales, que hace inviable diseños teóricos abstractos y transposición mimética de experiencias ajenas. Ello, unido a la tendencia al mantenimiento de lo existente y al continuismo en lo heredado y a la dependencia en gran medida de la alteración del modelo de los agentes sociales implicados en la negociación tal vez puedan explicar con notable exactitud la situación comentada.

Los factores jurídicos, con ser importantes, no son los únicos que explican la configuración y evolución de la estructura de la negociación colectiva, pues ésta responde a una pluralidad de 
Jesús Cruz Villalón, Patrocinio Rodríguez Ramos / Primeras valoraciones acerca de los efectos de la reforma laboral de 2012 en materia de estructura de la negociación colectiva en España

factores adicionales; factores de tipo económico, de estructura empresarial, de intensidad en las opciones de descentralización productiva, de reparto territorial del mercado de trabajo, de evolución de los sectores productivos, de conformación de las organizaciones de representación de los intereses colectivos, de configuración del poder político del Estado, etc., influyen con fuerza sobre la estructura de la negociación colectiva en su conjunto. Junto a estos factores, razones de orden sociológico e histórico muestran importantes resistencias al cambio en las prácticas negociales, y ejercen una intensa labor de mantenimiento y conservación de la configuración de la estructura de la negociación colectiva. La resistencia al cambio conecta de manera muy estrecha con la propia configuración de las organizaciones sindicales y patronales, pudiendo afirmarse al límite que la estructura de la negociación colectiva refleja la estructura de estas organizaciones, y que el carácter centralizado o descentralizado de la negociación colectiva en un determinado territorio permite intuir la naturaleza más o menos jerarquizada de las mismas.

Desde otra perspectiva, transcurrido un cierto tiempo desde que las reformas son aprobadas, resulta obligado atender a las labores de interpretación normativa que de manera progresiva realizan las distintas instancias judiciales. $Y$ si bien algunas de las nuevas reglas introducidas por la reforma de 2012 conceden escaso margen a la interpretación judicial, no conviene ignorar que determinados aspectos están siendo ya objeto de las primeras resoluciones de los órganos judiciales que, en breve, deberán establecer la doctrina jurisprudencial sobre tales aspectos. Esta jurisprudencia, en fase de creación, modulará en un futuro también de manera más o menos intensa los efectos reales de la reforma y su recepción por la negociación colectiva.

\subsection{El PAPEL DE LA NEgOCIACIÓN COLECTIVA EN EL DISEÑO DE LA ESTRUCTURA}

En consonancia con lo anterior, un elemento de singular trascendencia para la efectiva consecución de los cambios proyectados es el de la vía o mecanismo a través de los cuales aquéllos se introducen. En materia de negociación colectiva y de diseño de su estructura el debate se ha centrado, y se centra, en el papel que a tales efectos corresponde a la norma legal y a la convencional. El problema puede ser analizado desde dos ópticas diferentes: una, de carácter puramente jurídico destinada a delimitar y desentrañar los límites que la norma heterónoma puede tener en la labor de diseño de la estructura negocial y de la relación entre los diversos niveles de negociación, en la medida en que se considere que ello forma parte del núcleo fuerte de la libertad de negociación y que, por ende, queda inmune a determinada intensidad de injerencia legal.

El Tribunal Constituciónal ya ha abordado la cuestión, pronunciándose de manera contundente sobre el particular, al hilo de la regla relativa a la prioridad aplicativa del convenio de empresa introducida por la reforma 2012, dando por válida la nueva previsión de prioridad no alterable por los acuerdos interprofesionales y convenios colectivos (STC 119/2014, de 16 de julio). No obstante, al margen de ello, hay otra vertiente del problema respecto de la que el análisis no es tan simple ni directo; nos referimos a la relativa a la efectividad real de la modificación impuesta por vía heterónoma. Si, al margen y con independencia de que la solución legal se encuentre respaldada constitucionalmente en determinados extremos, los agentes negociadores tienen asumido, interiorizado y consideran que a ellos debería corresponder el diseño con plena libertad de la estructura negocial, de modo que cualquier interferencia legal que imponga en términos absolutos el diseño, encontrará el rechazo consiguiente de quienes hayan sufrido la limitación en la que consideran su libertad de contratación, representando, por tanto, un fuerte obstáculo al desarrollo e implementación práctica de los cambios introducidos legalmente. Ello es especialmente relevante 
respecto a la reforma llevada a cabo por el legislador en el año 2012, particularmente cuando la misma viene a "superponerse" a las medidas y criterios consensuados y articulados por los agentes sociales en el II Acuerdo para el Empleo y la Negociación Colectiva de 25 de enero de 2012. En tanto que los principios, reglas e intereses a los que responda la modificación legal choquen con los atendidos por los agentes sociales en su autónomo diseño del modelo y estructura de la negociación colectiva, aquél podría encontrar serios impedimentos para su eficaz puesta en práctica. Claro está que ello es así siempre que la confrontación se produzca entre los dos bloques en su conjunto, es decir, boceto legal versus boceto convencional, pues, en tanto el primero haga suyo o se incline hacia intereses concretos de una de las dos partes que han participado en el modelo autónomo, lógicamente, el juego de desencuentros se transforma (y el equilibrio de los intereses alcanzado en la transacción), aunque desde el punto de vista de la efectividad de la norma sigan existiendo problemas, eso sí, ahora de fisonomía algo diversa. Desde la otra perspectiva, también puede argumentarse, en términos puramente prácticos y soslayando problemas de legitimidad en la opción, que el abandono absoluto o la disponibilidad final por los agentes sociales de las reglas y directrices fijadas desde la norma legal en materia de estructura de la negociación colectiva puede hacer que, en la práctica, éstas, debido a la acción u omisión de organizaciones sindicales y empresariales, tenga un menor impacto.

\subsection{AlgunOS EJEMPLOS DE INTERACCIÓN ENTRE REgULACIÓN LEGAL Y DISEÑo CONVEN- CIONAL}

De la singular interacción y condicionamiento mutuo entre previsión legal, diseño convencional y eficacia real del modelo y estructura de la negociación colectiva, existen algunos ejemplos previos a la última reforma de 2012 dignos de ser tenidos en cuenta. No obstante, tales ejemplos se sitúan en un escenario algo diverso al que va a instaurar la reforma de 2012 pues aquéllos vienen a manifestar respuestas diversas (de rechazo, falta de implementación o solución negociada contraria) de la negociación colectiva a un concreto intento de la norma heterónoma de diseño de la estructura de la negociación, mientras que algunas de las prescripciones de la reforma de 2012, señaladamente la relativa a la prioridad aplicativa del convenio de empresa, lo que vienen a establecer es justamente la imposibilidad material de que vía convencional se actúe en forma diversa a lo previsto legalmente. De esta forma, no se trata tanto de una divergencia de los criterios rectores del modelo previsto por la norma y el llevado a la práctica por los agentes sociales, en un contexto donde este último es posible y viable, cuanto de una proscripción expresa a la eventual solución alternativa de los agentes negociadores.

La apuesta por un modelo de negociación colectiva articulada de carácter distributivo del Acuerdo Interconfederal sobre Negociación Colectiva de 27 de abril de 1997, chocó en su puesta en práctica con un diseño negocial dibujado por el legislador de la reforma de 1994 que respondía a criterios no coincidentes con los propugnados por los agentes sociales y cuyas "dinámicas centrífugas" éstos no supieron vencer. Y, de igual forma, la reforma operada en las reglas de concurrencia por la reforma de 1994, facilitando y promoviendo un marco autonómico de relaciones laborales, significó, amén de un obstáculo a los intentos de articulación de la negociación colectiva por los grandes acuerdos interconfederales (a lo que, la apertura a un proceso de "descentralización en cascada" del sistema de negociación y a un singular desarrollo del convenios colectivo de nivel provincial. A ello contribuyó la interpretación jurisprudencial que configuró la nueva regla de excepción a la prohibición general de concurrencia convencional como una norma de orden 
Jesús Cruz Villalón, Patrocinio Rodríguez Ramos / Primeras valoraciones acerca de los efectos de La reforma laboral de 2012 en materia de estructura de la negociación colectiva en España

público, de aplicación preferente respecto a lo establecido vía acuerdos y convenios (art. 83.2 ET). La norma no consiguió, pues, los objetivos perseguidos y, al tiempo, provocó unos resultados a la larga considerados mayoritariamente como perniciosos y disfuncionales para el modelo de negociación colectiva. Así pues, al margen del debate acerca de cuál ha de ser el papel y función de la norma heterónoma en la configuración del modelo y estructura de la negociación colectiva y de la intensidad y grado de "dirigismo" legal en la materia, lo cierto es que, producida la intervención normativa, los fines y propósitos buscados con su aprobación, pueden, por mor de prácticas y actitudes concretas de los destinatarios de la norma y protagonistas de la negociación colectiva, a veces no necesariamente ejecutadas con voluntad expresa de reacción frente a la previsión legal, conducir a resultados no queridos, en ocasiones, ni siquiera previstos por la reforma. Ello habrá de ser tenido muy presente a la hora de comprender los cambios realizados por la reforma de 2012 en la regulación de la estructura de la negociación colectiva y su real incidencia y eficacia práctica, por cuanto que la misma norma, consciente de este fenómeno, se presente ahora como imperativa y no facilite que la misma sea contradicha por parte de los acuerdos interprofesionales.

\subsection{FINES Y OBJETIVOS EXPLÍCITOS E IMPLÍCITOS DE LA REFORMA LABORAL DE 20 I 2}

A tenor de lo expuesto, resulta, pues, de todo punto pertinente, indagar acerca de cuáles son los fines y objetivos que la reforma de 2012 en materia de estructura de la negociación colectiva pretende alcanzar. Bajo la premisa constatada y unánimemente aceptada de las graves disfunciones que aquejan a nuestro modelo de negociación colectiva, la reforma de 2012, según lo que se desprende de su exposición de motivos, trata de incorporar una serie de "medidas para favorecer la flexibilidad interna en las empresas como alternativa a la destrucción de empleo"; "fortalecer los mecanismos de adaptación de las condiciones de trabajo a las circunstancias concretas que atraviese la empresa", y, en particular, por lo que respecta a la negociación colectiva, procurar que ésta "sea un instrumento, y no un obstáculo, para adaptar las condiciones laborales a las concretas circunstancias de la empresa". Más en concreto, descendiendo a la temática de la estructura de la negociación colectiva, se indicará, si bien de forma indirecta y como propósito compartido con la reforma precedente de 2011, que se busca incidir en ella, "otorgando prioridad aplicativa al convenio de ámbito empresarial sobre otros convenios en una serie de materias que se entienden primordiales para una gestión flexible de las condiciones de trabajo". Es decir, lo que verdaderamente se busca es la gestión flexible de las condiciones de trabajo que, desde el punto de vista de su fuente reguladora, se entiende más fácil si proceden del convenio de empresa que de una norma convencional de ámbito superior. La pretensión legal declarada, era, pues, la de fomentar la negociación colectiva a nivel de empresa; fomento que para el legislador está motivado en el deseo de facilitar la adaptación de las condiciones de trabajo al concreto contexto empresarial, incrementando la flexibilidad en la gestión de las relaciones laborales y evitando con ello la destrucción de empleo.

No obstante, a estos fines expresos y explícitos, alguna doctrina, en crítica abierta a una exposición de motivos y una reforma que se llega a tildar de "esquizofrénica" en cuanto a la diferencia existente entre lo que se dice y lo que realmente se hace, ha añadido otros objetivos implícitos ligados a la reducción de costes laborales y, más particularmente, dirigidos a la devaluación salarial, que, vía negociación colectiva empresarial, se presume más factible. 


\section{LAS NUEVAS REGLAS DE ORDENACIÓN DE LA ESTRUCTURA DE LA NEGOCIACIÓN COLECTIVA}

\subsection{EL FOMENTO DEL CONVENIO DE EMPRESA}

Conviene detenerse ahora en las transformaciones realizadas por la reforma de 2012 en materia de estructura de la negociación colectiva, no sin antes indicar que tales modificaciones han sido objeto de un extenso tratamiento y análisis por parte de la doctrina iuslaboralista que, en muchos casos, se ha manifestado crítica con el enfoque con el que determinados preceptos han sido reelaborados.

El fomento y la apuesta de la reforma de 2012 por la negociación colectiva a nivel de empresa se traduce, en lo que respecta a la estructura de la negociación colectiva, en la alteración de los términos en los que estaba regulada la materia tras la reforma de 2011. Así, la reforma de 2012 transforma el carácter supletorio de la regla de la prioridad aplicativa del convenio de empresa, introducida por la reforma de 2011, en norma de orden público laboral, inexpugnable a la acción de la autonomía colectiva y expresamente declarada como indisponible para los acuerdos y convenios colectivos. Tras la reforma de 2012, la regulación establecida en los convenios de ámbito superior a la empresa podrá ser afectada por lo que disponga un convenio colectivo de empresa, en cualquier momento; eso sí, en este caso la afectación no se extiende sobre la totalidad del convenio si bien lo hace respecto de las materias más importante y, por tanto, de mayor impacto en la funcionalidad del convenio colectivo. En concreto, la regulación de las condiciones establecidas en un convenio de empresa, de grupo de empresa o de una pluralidad de empresas nominativamente identificada tendrá prioridad aplicativa respecto del convenio sectorial en las siguientes materias: a) la cuantía del salario en sus diferentes partidas; b) el horario y la distribución de los tiempos de trabajo y de descanso; c) la adaptación del sistema de clasificación profesional; d) la adaptación de las modalidades de contratación; e) las medidas para favorecer la conciliación entre la vida laboral, familiar y personal. Adicionalmente, a través de los acuerdos y convenios colectivos se podrán establecer otras materias adicionales para las que se aplique la preferencia aplicativa del convenio colectivo, pero en cambio se prohíbe que a la inversa dichos acuerdos y convenios puedan alterar la preferencia aplicativa del convenio de empresa otorgando mayor preponderancia al convenio sectorial (art. 84.2 ET).

Junto a esa regla primera de estructuración de la negociación colectiva en que se ha convertido la prioridad aplicativa del convenio de empresa, en la tradicional técnica de sedimentación normativa, perviven el resto de las reglas tradicionales en nuestro sistema de concurrencia convencional. Así, la segunda regla legal en materia de articulación y concurrencia de convenios tiene que ver con la ordenación de las relaciones entre los distintos niveles de negociación y la garantía de la eficacia vinculante de lo negociado y su inalterabilidad frente a la irrupción como novedosa de otra unidad de negociación. A tales efectos, se sigue estableciendo que un convenio colectivo durante su vigencia no puede ser "afectado" por lo dispuesto en convenios de distinto ámbito (art. 84.1 ET). Este segundo principio general se ve matizado por dos reglas específicas, que actúan como regla especial. La primera, que las partes mencionadas expresamente por la norma (organizaciones sindicales y asociaciones empresariales más representativas, a nivel Estatal o de Comunidad Autónoma -y sindicatos y asociaciones empresariales legitimadas para negociar convenios sectoriales de ámbito estatal o autonómico-) pueden disponer reglas distintas de concurrencia, y, 
Jesús Cruz Villalón, Patrocinio Rodríguez Ramos / Primeras valoraciones acerca de los efectos de la reforma laboral de 2012 en materia de estructura de la negociación colectiva en España

por tanto, mediante acuerdos interprofesionales o convenios sectoriales estatales o autonómicos pueden establecer reglas de afectación entre los distintos niveles, lo que suaviza claramente la eficacia de este principio (art. 83.2 ET). Eso sí, con la importante aclaración de que ello en ningún caso puede afectar a la preferencia aplicativa del convenio de empresa. De otra parte, y salvo pacto en contrario en los mismo términos recién comentados, se contemplan criterios de solución de la concurrencia entre convenios sectoriales estatales y de Comunidad Autónoma, para establecer la preferencia aplicativa de estos últimos respectos de los estatales si bien con ciertas excepciones para una relación de materias (art. 84.3 y 4 ET).

La conjunción de estas reglas desemboca en un criterio implícito en negativo, consistente en que el legislador pretende postergar y, por tanto, intentar reducir al máximo la capacidad de influencia del ámbito convencional nunca mencionado: el convenio colectivo provincial. Como ya hemos señalado, este ámbito ha tenido una muy extendido influencia a lo largo de varias décadas pero ahora se considera poco apropiado desde el punto de vista económico y de diseño general de nuestras relaciones laborales, desde el instante en que se favorece bien un sistema centralizado (convenio estatal), o descentralizado (empresa), pero en ningún caso intermedio (provincial).

\subsection{LA ACTUAL ORDENACIÓN LEGAL DE LA ESTRUCTURA SUPRAEMPRESARLAL-SECTORIAL}

De esta forma, la ordenación legal de la estructura supraempresarial-sectorial en la actualidad queda marcada por el juego conjunto de la reglas legales y su posible alteración vía acuerdo por parte de los propios negociadores. Así, salvo pacto en contrario, se permite la afectación por los convenios de sector en el ámbito de una Comunidad Autónoma (no dejando del todo claro el legislador si se refiere exclusivamente al ámbito territorial autonómico o si, por el contrario, también incluiría a otros ámbitos infraautonómicos, como el provincial) de lo establecido por los convenios sectoriales de ámbito estatal. En tales supuestos, y salvo disposición en contrario, el legislador fija una serie de materias no negociables. Esta última previsión de salvedad, reservada en exclusiva al ámbito estatal, viene a representar una regla de potencial "re-centralización" de nuestra estructura de negociación colectiva dejada a la voluntad de los interlocutores estatales. Así pues, por lo que se refiere a los niveles supraempresariales, puede entenderse que se mantiene las reglas de pasado que apuestan por dotar a la estructura de la negociación colectiva de un mayor grado de centralización, que queda plasmado en el reconocimiento a los negociadores del ámbito estatal de la facultad de diseñar la estructura de la negociación colectiva, salvo por lo que se refiere a la prioridad aplicativa reconocida al nivel empresarial.

\section{OTROS ELEMENTOS ADICIONALES DE LA NEGOCIACIÓN AFECTADOS POR LA REFORMA}

Además de la ya apuntada incidencia de la reforma de la negociación colectiva sobre su estructura y reglas de concurrencia, significativamente en lo relativo a la preferencia aplicativa absoluta del convenio colectivo de ámbito empresarial frente a cualquier tipo de convenios sectoriales, hay dos elementos configuradores adicionales sobre los que se ha centrado la reforma de la negociación colectiva en España, en el marco de la crisis económica: la pérdida de vigencia del convenio colectivo y el procedimiento de inaplicación del convenio colectivo

La primera de las materias refiere a la aplicabilidad del convenio colectivo una vez transcurrido el período de vigencia pactado, cuestión muy influyente por cuanto que es habitual en 
España que la renovación de los convenios colectivos se demore en el tiempo, de modo que tiene a existir un amplio período de tiempo entre la terminación del convenio y la firma del nuevo que lo sustituye. Pero resulta especialmente influyente este asunto por cuanto que el mismo incide decisivamente sobre la posición de las partes en el proceso de renegociación del convenio colectivo, pues su capacidad de presión es bien diferente según cuál sea el régimen jurídico de ese período de tránsito entre uno y otro convenio. La regla prevista sobre esta materia en la normativa legal tradicionalmente ha tenido carácter supletorio, por tanto con posibilidad de ser alterada por pacto entre las propias partes negociadoras, si bien hasta el momento presente se aplicaba de manera generalizada respecto del conjunto de las unidades negociales. De forma resumida, la regla que regía hasta tiempo reciente permitía un una aplicación ultraactiva del convenio colectivo cuya vigencia concluía hasta tanto se firmase un nuevo convenio que lo sustituyese; dicho en otros términos, denunciado el convenio colectivo cuya vigencia concluía, se mantenía su aplicación a todos los efectos de manera indefinida hasta la entrada en vigor del nuevo convenio. Esta fórmula garantizaba la plena cobertura convencional del régimen de condiciones de trabajo pactado, no provocaba ninguna incertidumbre ni preocupación respecto de la hipótesis de bloqueo en la renegociación del nuevo convenio colectivo, al tiempo que otorgaba una posición fuerte a la representación sindical en la medida en que acudían a la negociación sin peligro de retroceso en las condiciones de trabajo ya pactadas. A partir de la reforma laboral acometida con la reforma laboral el panorama cambia sustancialmente, por cuanto que ahora sólo se prevé una vigencia ultraactiva del convenio denunciado, limitada por un año; transcurrido ese año de existir se aplicaría el convenio colectivo de ámbito inferior, pero en todo caso pierde vigencia aplicativa el antiguo convenio colectivo concluido finalmente en su vigencia (art. 86.3 ET).

La segunda de las medidas establecidas consiste en la introducción de un procedimiento que permite la inaplicación de las condiciones de trabajo pactadas en los convenios colectivos cuando en una específica empresa surjan causas económicas, técnicas, organizativas o productivas que así lo justifiquen. Este mecanismo, conocido con la denominación de "descuelgue" convencional, existe en el ordenamiento español desde los inicios de la década de los años noventa. Sin embargo, la novedad se encuentra en la forma como se puede llegar a ese resultado de incumplimiento de lo pactado en el convenio colectivo: mientras que el sistema se basaba hasta el presente en el principio de la voluntariedad, de modo que se exigía en todo caso el acuerdo entre las representaciones sindicales y de la empresa para proceder a la inaplicación, a partir de la reforma ello es posible que se produzca por la mera iniciativa de la parte empresarial y sin el consenso sindical. En concreto, se permite que la representación empresarial someta la cuestión a un arbitraje obligatorio público, que por medio de laudo debe acordar la inaplicación del convenio en caso de que concurran las causas empresariales referidas (art. 82.3 ET).

Las tres medidas de reforma fueron contestadas por las organizaciones sindicales y, especialmente las relativas a la preferencia aplicativa del convenio de empresa y a la inaplicación de convenios colectivos, fueron consideradas por parte de la doctrina iuslaboralista como contrarias a la fuerza vinculante de los convenios colectivos y a la libertad sindical, ambos como derechos consagrados en la Constitución Española. No obstante, el Tribunal Constitucional español (SSTC 119/2014, de 16 de julio, BOE 15 de agosto; 8/2015, de 22 de enero, BOE 24 de febrero), como ya hemos apuntado, ha avalado la constitucionalidad de la reforma legislativa en estos dos elementos claves. 
Jesús Cruz Villalón, Patrocinio Rodríguez Ramos / Primeras valoraciones acerca de los efectos de la reforma laboral de 2012 en materia de estructura de la negociación colectiva en España

\section{LOS PRIMEROS EFECTOS DE LA REFORMA DE 2012}

\subsection{LO QUE DICEN LOS DATOS ESTADÍSTICOS}

\subsubsection{Cautelas en su valoración: carencia e insuficiencia de los datos}

En relación a los primeros efectos y resultados que la reforma de la estructura de la negociación colectiva en 2012 está provocando, vamos a centrar el análisis cuantitativo y de datos estadísticos en los siguientes factores que, a la postre, se suelen considerar como más relevantes y significativos en la configuración de un determinado modelo negocial, a saber, su tasa de cobertura, la distribución entre las diversas unidades y niveles de negociación y el número de empresas y trabajadores afectados por cada unidad de negociación. A ellos añadiremos, por lo que de contrapeso puede representar en el diseño general del sistema y en tanto su desarrollo ha sido objeto de fomento por la reforma de 2012, el dato relativo a las inaplicaciones y descuelgues de convenios colectivos.

Antes de entrar en el análisis detallado hemos de realizar algunas indicaciones y consideraciones generales sobre las fuentes estadísticas y el valor de los datos de los que se dispone. Una evaluación global de los datos estadísticos oficiales proporcionados por la Administración laboral permite afirmar la existencia de notables carencias y lagunas, que hacen difícil conocer qué impacto real está teniendo la reforma. Nos movemos en un terreno ciertamente resbaladizo y de notable inseguridad y ello porque: 1) los datos relativos al número de trabajadores afectados por la negociación colectiva se extraen de la hoja estadística de convenios colectivos que, por lo que se refiere a los convenios de ámbito sectorial, a diferencia de lo parece acontecer respecto a los convenios de empresa, no resultan de gran fiabilidad. De igual forma, no es seguro que esas hojas estadísticas reflejen la importante caída en el empleo que se ha producido en los últimos años, especialmente en algunos sectores, y no resulta descabellado aventurar que, en no pocas ocasiones, el dato del número de trabajadores afectados por el convenio en cuestión se haya cumplimentado en los mismos términos que se recogían en la hoja estadística del precedente convenio sin reparar en la situación real del empleo. A estos afectos tampoco queda claro cómo se refleja en el cómputo de trabajadores afectados por el convenio eventuales procesos de descuelgues. Todos estas circunstancias condicionan en gran medida, algunas a la baja y otras al alza, el cálculo de variables como la de la tasa de cobertura; 2 ) los datos obvian la realidad de que nuestro sistema de negociación posee un cierto grado de articulación, por tanto de que para ciertos trabajadores y empresas existan varios convenios colectivos aplicables simultáneamente si bien lo sean respecto de materias diversas, por lo que no es extraño que se produzcan duplicidades en la contabilización de determinados colectivos de trabajadores; 3) no cabe valorar la estructura global de la negociación colectiva sin tener en cuenta la presencia e incidencia de resultados de procesos de negociación como los que suponen los acuerdos de empresa, sobre los que no existen datos estadísticos de referencia; 4) los datos estadísticos se obtienen con un notable retraso, no estimándose como definitivos hasta pasados dos años desde la fecha sobre la que se estiman, por lo que su evaluación $\mathrm{y}$ valoración antes de tal momento debe realizarse con notable cautela. 


\subsubsection{La tasa de cobertura}

En relación a la tasa de cobertura de la negociación colectiva, definida como la relación entre los trabajadores realmente cubiertos por la negociación y el total de trabajadores que potencialmente pueden estarlo, el sistema español de negociación colectiva se ha caracterizado históricamente por unos niveles elevados de cobertura de la negociación colectiva, cifrándose por parte de algunos estudios en torno al 80-85\%, y situándose España a nivel internacional como uno de los países con mayor tasa de cobertura de la negociación. Las causas de esta elevada tasa de cobertura de la negociación colectiva española se han residenciado en los principios básicos de su configuración normativa, en particular en la eficacia general o erga omnes del convenio colectivo. Esta eficacia general, unida al carácter normativo del convenio, al tradicional juego que la regla de la ultraactividad ha tenido en nuestro ordenamiento jurídico hasta fechas recientes, y a un tejido empresarial de microempresas en donde el fuerte peso del convenio sectorial funcionaba como paraguas protector, han permitido y explicado esos altos índices de cobertura de la negociación. Permaneciendo el resto de los elementos que propician las altas tasas de cobertura, el único elemento de los previamente mencionados que ha podido influir a partir de la reforma de 2012 es el relativo a la ultraactividad, en la medida en que esta ha limitado su carácter indefinido, lo que desde de los primeros análisis fue considerado como un potencial factor determinante de un paulatino descenso de los niveles de cobertura convencional. Sin embargo, a estas alturas no hay datos concluyentes al respecto.

Teniendo en cuenta el número de asalariados de la EPA, la tasa de cobertura se sitúa entre el $80 \%$ y el $77 \%$ a lo largo de los últimos años, coincidiendo con el período de crisis económica. Con independencia de los parámetros utilizados y las diferencias que de ello se derivan, lo cierto es que se observa una cierta tendencia de descenso de la tasa de cobertura a partir de 2009. Resulta arriesgado utilizar en estos momentos los datos correspondientes a 2013 y 2014 , dado que se trata de datos provisionales, de modo que sólo se puede trabajar con intuiciones respecto de lo que se está produciendo a resultas de la reforma laboral de 2012. Con todo, como línea de tendencia, parece apreciarse un descenso en la tasa de cobertura en los últimos años, sin que aún se pueda determinar su alcance cuantitativo definitivo ni de si se trata de un fenómeno estructural o coyuntural, ni si se va a prolongar en el tiempo en similar dirección descendente o, por el contrario, se va a producir una cierta reversión (o estabilización) en las cifras de cobertura tras esa primera minoración. Tampoco es fácil discernir si tal efecto es consecuencia de la persistencia de la crisis económica y sus consecuencias directas e indirectas en los procesos de negociación, de la reforma legal en materia de negociación o de los dos factores a la vez; ni, en este último supuesto, cuál sería el peso relativo de cada uno de tales factores de incidencia.

Más complejo aún resulta determinar cuáles pudieran ser los factores o elementos que han propiciado esa caída en la tasa de cobertura; la ausencia de datos que permitan desagregar dicha tasa por sectores de actividad, territorios o niveles de negociación tampoco ayuda en la tarea de aventurar hipótesis explicativas. Pero más aún, en la realidad práctica, la percepción los agentes sociales es que tal reducción no se ha producido o cuanto menos no aciertan a determinar en qué modo o grado. A modo de ensayo teórico de posibles conjeturas que aclaren esta situación podrían mencionarse las siguientes: pudiera suceder que si bien formalmente el convenio colectivo haya decaído y, por tanto, los trabajadores afectados se contabilicen como no cubiertos, en la práctica se sigue aplicando la norma convencional (contractualizada) de forma transitoria y en espera de que tal vez en un futuro se logre un nuevo acuerdo. Esta posibilidad parece que es bastante real y, en términos cuantitativos, nada desdeñable. Otra opción pudiera ser la de que los acuerdos de em- 
Jesús Cruz Villalón, Patrocinio Rodríguez Ramos / Primeras valoraciones acerca de los efectos de la reforma laboral de 2012 en materia de estructura de la negociación colectiva en España

presa hubieran pasado a sustituir al convenio en la labor reguladora. Aunque algún fenómeno de esta índole se haya producido, la fisonomía singular de tales acuerdos y el papel que cumplen no parece que convierta a esta explicación en relevante a la hora de justificar la disminución de la tasa de cobertura. También pudiera pensarse, con bastante probabilidad de certeza, que la manifiesta falta de dinamismo y agilidad de la negociación colectiva en los dos últimos años haya provocado que, mientras que en otros momentos se ha sido mucho más diligente y rápido en la labor de dar cobertura a las nuevas empresas y sectores de actividad que van surgiendo fruto de los cambios productivos y organizativos de las empresas, ahora ese cometido se esté desarrollando con mucha mayor demora. Eventualmente pudiera igualmente pensarse que se esté produciendo un trasvase de cobertura desde el convenio estatutario al extraestaturio, si bien es una hipótesis a descartar absolutamente, porque no hay ningún dato que apunte en esta dirección. Tampoco tendría mucho éxito a nuestro juicio razonar en términos de afirmar que ámbitos y sectores tradicionalmente no cubiertos por la negociación colectiva ha sufrido un proceso significativo de incremento del número de asalariados. Un argumento de mayor peso sería el que tomara en consideración el dato de que si bien la cobertura de la negociación vía extensión de convenios colectivos no ha sido nunca especialmente significativa, sí ha tenido alguna presencia que, sin embargo, en los últimos años ha desaparecido totalmente.

\subsubsection{Los niveles de negociación}

Respecto a los diversos niveles de negociación, la situación de partida era que, medido en término de número de convenios, el nivel de negociación predominante era el de empresa; supremacía en términos absolutos, que, no obstante, no se trasladaba al parámetro del número de empresas y trabajadores cubiertos por tal nivel convencional, puesto que en España un porcentaje muy alto de empresas y de trabajadores estaban cubiertos por convenios sectoriales, siendo entre éstos los más relevantes los provinciales. En los últimos años, la tendencia general en la evolución del número de convenios según niveles es la de una disminución progresiva de la cifra de convenios registrados desde 2008 a 2012 a todos los niveles, pero mientras que la reducción experimentada por los convenios de empresa es del $41,07 \%$, los convenios sectoriales provinciales sufren una disminución algo inferior, del $37,88 \%$, y los sectoriales nacionales un descenso mucho menos acusado, del $23,23 \%$. Si avanzamos el análisis a un período temporal superior e incluimos el año 2013, al objeto de examinar la incidencia de la reforma de 2012, con datos como venimos insistiendo aún provisionales, se confirma y acrecienta la tendencia de la disminución en el número de convenios registrados, tanto a nivel de empresa como en general en el resto de niveles negociales. De igual forma, si analizamos la variación porcentual en el período 2011-2013 del número de convenios según nivel, observamos què los convenios de empresa experimentan una disminución porcentual del 65,49 , muy superior tanto a la disminución sufrida por los convenios sectoriales provinciales (del $57,56 \%$ ) como a la de los convenios sectoriales nacionales $(43,04 \%)$.

Con menor nivel de desagregación pero con datos más actualizados (convenios registrados hasta julio de 2014), la evolución del número de convenios registrados según su ámbito vuelve a poner de manifiesto la reducción importante en el número de convenios registrados que se ha venido produciendo en los últimos años, tanto a nivel de empresa como de ámbito superior. Eso sí, con resultados más actualizados, el porcentaje de disminución de convenios registrados es, como cabía esperar, algo inferior. En todo caso, una vez más hay que llamar la atención sobre el riesgo de utilizar los datos más actualizados debido a su falta de fiabilidad dada su provisionalidad. 
Al objeto de evaluar la incidencia de la reforma de 2012 en lo que respecta al fomento de la negociación colectiva a nivel de empresa, la comparación entre la diferencia en el descenso porcentual experimentado por los convenios de empresa y los de ámbito superior en el período 2008-2012 y la que se produce en dichos niveles en el tramo temporal 2011-2013 arroja el siguiente resultado, con todos los riesgos derivados de la provisionalidad de los datos: se produce una disminución de 2,01 puntos porcentuales en ese superior descenso del número de convenios de empresa registrados frente a los de ámbito superior en el período 2011-2013 frente al período 2008-2012. Lo anterior es acorde con el inferior aumento del porcentaje de descenso de los convenios de empresa en el período 2011-2013 respecto al período 2008-2012 (14,71 puntos porcentuales -un -51,08\% frente a un -36,37\%-) que ofrecen los datos más actualizados si los comparamos con lo acontecido respecto a los convenios de ámbito superior (16,72 puntos porcentuales -un $-40,06 \%$ frente a un $-23,34 \%$-). Teniendo en cuenta lo expuesto y las características de las fuentes utilizadas, y con las debidas cautelas, parece que en los últimos meses se ha producido un perceptible incremento en el número de convenios de empresa que se han registrado respecto a los de otro ámbito.

Si analizamos el porcentaje de convenios de empresa sobre el total de convenios, se comprueba que en el período 2000-2011 dicho porcentaje sufre un proceso progresivo de pequeño aumento (desde el $73,28 \%$ en 2000 hasta el $76,42 \%$ en 2007 , con una ligera distorsión en el año 2004) hasta el año 2007 para, a partir de tal fecha, ir disminuyendo paulatinamente en términos generales; tendencia de disminución progresiva en el porcentaje de convenios de empresa sobre el total que se sigue manteniendo en los años sucesivos, pues, aún con datos provisionales, en 2012 tal porcentaje desciende al 72,24\% y en 2013 al 70,6\%. Es decir, los descensos son incluso más acusados que en años procedentes (2,39 puntos porcentuales entre 2011 y 2012 y 1,64 puntos porcentuales entre 2012 y 2013 frente a los 0,95 puntos porcentuales entre 2009 y 2010 y el 0,4 punto porcentual entre 2010 y 2011). Si no hemos errado en la consideración anterior, habría que concluir que el aumento del número de convenios de empresa en los últimos meses no ha llegado a ser de nivel tal que logre incrementar el porcentaje de convenios de empresa sobre el total en relación a la situación precedente a la última reforma.

Si atendemos al dato del número de convenios, no en función del año de efectos económicos sino del año de firma, los datos indican que durante 2012 se ha producido un importante incremento en el número de convenios de empresa firmados sobre el total de convenios en relación a la cifra de 2011, en tendencia que parece consolidarse y estabilizarse en 2013 (los datos aún son muy provisionales), pues el porcentaje de convenios de empresa firmados en dicho año sobre el total de los firmados sigue siendo de casi 15 puntos $(14,62)$ porcentuales superior a la cifra correspondiente a 2011. Ahora bien, el análisis de los datos correspondientes a los trabajadores afectados por las diversas unidades negociales pone de manifiesto que el porcentaje de trabajadores afectados por convenios de empresa según año de firma, ha ido disminuyendo desde 2011 a 2013, pues mientras en 2011 fue del 9,58\%, en 2012 bajó al 9,02\% y, en 2013, se sitúa, de momento pues pueden existir variaciones, en el 6,92\%. La comparación de estos resultados con los obtenidos respecto al incremento porcentual de los convenios de empresa firmados a lo largo de estos años lleva a la conclusión de que el aumento de convenios de empresa se está produciendo en unidades empresariales de pequeñas dimensiones en lo que a número de trabajadores respecta.

Para confirmar los anteriores resultados y teniendo en cuenta el carácter provisional de los datos de los que se disponen y el escaso tiempo transcurrido desde las últimas reformas normativas, se ha examinado el número de convenios firmados en los últimos años que suponen la aparición de nuevas unidades de negociación. Y se ha observado que la evolución de la creación de 
nuevas unidades de negociación a nivel de empresa es claramente ascendente desde 2011 a 2014 , incrementándose un $129,3 \%$ entre 2011 y 2014, en una tendencia que parece mantenerse pues entre 2013 y 2014 se experimenta un aumento en las nuevas unidades de negociación de nivel de empresa del 5\%. Por lo que respecta a las nuevas unidades sectoriales, entre 2011 y 2014 la tendencia es decreciente, pues entre 2011 y 2014 sufre un descenso del $37,5 \%$.

Mención especial merece la evolución del número de nuevos convenios de grupo de empresas, pues con datos a diciembre de cada año, entre el año 2011 y el 2013 sufren un aumento del $375 \%$. Si añadimos el año 2014 y tomamos los datos referenciados a julio de cada año, la situación es también muy elocuente pues el incremento sería del $200 \%$. Con todo no conviene obviar que en términos absolutos el volumen de convenios de grupos de empresas se mueve en guarismos muy bajos ( 2 nuevas unidades en 2011, 3 en 2012, 5 en 2013 y 6 en 2014). Por otro lado, un extremo que los datos no ofrecen ni clarifican es el de hasta qué punto estos convenios de grupos de empresa responden realmente a grupos de empresas reales y fisiológicos o, por el contrario, incorporan también fenómenos patológicos de grupos de empresas en los que realmente existe una única empresa desde el puntos de vista productivo y organizativo.

Si el parámetro a considerar es el del porcentaje de nuevas unidades de cada nivel sobre el total de nuevas unidades, se observa que el correspondiente a los convenios de empresa ha evolucionado al alza desde el 90,20\% en 2011 al 95,04\% en 2014, mientras que el porcentaje de nuevas unidades sectoriales sufre un descenso para pasar del 7,84\% en 2011 al 2,25\% en 2014. Por su parte, el porcentaje de nuevas unidades de grupo de empresas también evoluciona al alza, si bien con cierta moderación, pasando del 1,96\% en 2011 al 2,70\% en 2014. En conclusión, puede afirmarse que en los últimos dos años las nuevas unidades de negociación que se crean son en un porcentaje muy elevado de nivel de empresa, mientras que las sectoriales, tras un brusquísimo descenso en 2012, han logrado experimentar un cierto aumento, si bien se mantienen en porcentajes muy inferiores a los de 2011. Por otro lado, la regulación y previsión legal expresa de las reglas de legitimación de los convenios de grupo de empresas llevada a cabo por la reforma de 2012 parece que ha tenido una significativa repercusión en el desarrollo y expansión de este nivel convencional. Aunque la doctrina judicial hubiera dado respuesta desde hacía tiempo a los requerimientos que en materia de capacidad y legitimación negocial se derivaban de la realidad práctica y económica de la existencia de esta unidad negocial, parece que la mayor seguridad jurídica representada por la su específica consagración legal ha propiciado su desarrollo.

Interesa destacar que, en atención a las nuevas unidades negociales aparecidas hasta el momento en 2014, un porcentaje importante de trabajadores están cubiertos por convenios de empresa; porcentaje que, unido al de los trabajadores afectados por convenios de grupo de empresas, llegan a representar casi la mitad (un 47,57\%) de los trabajadores cubiertos por la nuevas unidades negociales.

\subsubsection{Número de convenios y de empresas y trabajadores afectados}

La evolución del número de convenios y de empresas y trabajadores afectados por la negociación colectiva había sido claramente creciente en España desde 1995, si bien a partir de 2008, parece producirse un cierto cambio de tendencia, que se consolidará en los años siguientes. Con datos definitivos, el número de convenios registrados en 2008 alcanzó la cifra de casi 6.000 (5.987), mientras que en 2010 apenas superan los 5.000 (5.067), y en 2011 ni siquiera se llega a los 4.600 (4.585). Si bien con datos aún provisionales, la tendencia parece se mantiene en 2012 y 2013 pues en el primer año ni se alcanza la cifra de los 4.000 convenios (3.998) y en 2013 ni siquiera se 
llega a los 2.500 (2.371). Igual conclusión cabe reseñar en lo relativo al número de empresas y trabajadores afectados por la negociación colectiva, que ha ido descendiendo paulatinamente en el período 2008-2011. Respecto al número de empresas afectadas, de 2008 a 2011, con datos definitivos, el descenso ha sido de casi un $30 \%(27,05 \%)$; y, si ampliamos el período a 2013 , aunque con datos provisionales, la disminución llega a casi el $40 \%$ (39,86\%). En lo relativo al número de trabajadores afectados por convenios, como ya expusimos al examinar la tasa de cobertura convencional, se ha producido un progresivo descenso desde 2008 a 2013. Con datos definitivos, el descenso entre 2008 y 2011 ha sido de 10,91\%; y, prolongando el período temporal a 2013, si bien con datos provisionales, la disminución alcanza el porcentaje del 42,04\%.

Si analizamos el dato del número de trabajadores afectados por convenio según ámbito funcional, y nos fijamos específicamente en los trabajadores cubiertos por convenios de empresa, el porcentaje de trabajadores afectados por convenios de empresa sobre el total ha ido disminuyendo desde 2008 a 2011 , pasando del $10,15 \%$ en 2008 al 8,71\% en 2011 , en una tendencia decreciente que, no obstante se quiebra en el tránsito de 2010 a 2011 donde se produce un ligero repunte. Ampliando el arco temporal e incluyendo los años 2012 y 2013, si bien con datos aún no definitivos, la tendencia se mantiene, y el porcentaje de trabajadores cubiertos por convenios de empresa sobre el total sigue decreciendo hasta la cifra del $6,56 \%$. Este dato puede explicar y concordar con el hecho de que si las nuevas unidades negociales de empresa se están incrementando y aun así el número de trabajadores afectados por convenios de empresa sobre el total sigue disminuyendo, ello es porque las nuevas unidades de empresa se refieren a empresas de muy pocos trabajadores.

Un parámetro de interés a efectos de delimitar la naturaleza de las unidades negociales empresariales es el de analizar la dimensión de la plantilla de las empresas afectadas por los diversos niveles de negociación colectiva. El tamaño de las empresas afectadas por convenios de empresa oscila entre 2008 y 2013 en una banda de plantilla de entre un mínimo de 242,8 (2010) y un máximo de 271,48 (2011) trabajadores. Empresas, por tanto, que, en atención al número de trabajadores de la plantilla, entrarían o estarían muy próximas en la categoría de gran empresa (calificación que suele otorgarse a las empresas con plantilla superior a los 250 trabajadores). Por el contrario, el tamaño medio de la plantilla de las empresas afectadas por convenios de ámbito superior a la empresa ha oscilado en dicho período entre un mínimo de 6,68 (2010) trabajadores hasta un máximo de 8,34 (2011) trabajadores. Es decir, empresas con plantillas mínimas para contar con representantes de los trabajadores de acuerdo con las previsiones legales. Puede que sea un dato a tener muy en cuenta, aunque es necesario esperar un tiempo pues aún se trabaja con cifras provisionales, el descenso en el número de trabajadores de las plantillas de las empresas cubiertas por convenios sectoriales entre el año 2012 y 2013 , donde se pasa de los 7,88 trabajadores a los 6,73 , pues ello puede significar que las empresas pequeñas están pasando a negociar sus propios convenios, quedando el nivel sectorial para las muy pequeñas o micro empresas, donde no se alcanzan las plantillas mínimas para tener órganos de representación estatutaria o unitaria.

El convenio sectorial provincial ha sido en el período 2008-2012, el que ha dado cobertura a empresas de menores dimensiones, en casi todos los años, salvo en 2011 y 2012, con plantillas inferiores a los mínimos legales para disfrutar de representación legal y, por ende, poder negociar convenios propios. Un dato llamativo es la evolución del tamaño promedio de las empresas afectadas por convenios sectoriales nacionales entre 2008 y 2012, pues casi se duplica la dimensión de las plantillas de tales empresas (de 7,40 en 2008 se pasa a 14,28 en 2012). Por su parte, es igualmente reseñable la evolución del tamaño promedio de las empresas cubiertas por convenios de grupo de empresas en el período 2008-2012, donde se pasa de afectar tal nivel de negociación a muy grandes empresas (de tamaño promedio de 346,66 trabajadores en 2010) para, a partir de 
Jesús Cruz Villalón, Patrocinio Rodríguez Ramos / Primeras valoraciones acerca de los efectos de la reforma laboral de 2012 en materia de estructura de la negociación colectiva en España

2011 y 2012 dar cobertura a unidades empresariales que no llegan a los 200 trabajadores $(190,43$ en 2011) o que, incluso, escasamente superan los 150 trabajadores (154,53 en 2012). Tal vez estos datos estén anticipando ese comportamiento, que viene a reforzar la reforma de 2012, en atención al cual las empresas de medianas y pequeñas dimensiones que pueden disfrutar de convenio propio salen del paraguas del sectorial nacional.

Con todo, tampoco puede descartarse que, como consecuencia de la crisis económica y la consiguiente destrucción de empleo que ha conllevado, el tamaño medio de las empresas de nuestro tejido empresarial haya sufrido un significativo proceso de disminución. De este modo, tales cifras deben ser necesariamente matizadas, dado que en el período de la crisis se ha producido en paralelo una disminución del número medio de trabajadores ocupados por empresa, de modo que desde 2008 hasta 2013 el tamaño medio se ha reducido en medio punto, pasando de 4,93 hasta 4,47 trabajadores por empresa.

\subsubsection{Los procesos de inaplicaciones y descuelgues de convenios colectivos}

A partir de la entrada en vigor de la reforma de 2012 se ha producido un incremento notable de procesos de inaplicaciones o descuelgues de convenios colectivos. En concreto, conforme a los datos oficiales hasta julio de 2014, desde la aprobación de la reforma se han producido un total de 4.792 inaplicaciones que han afectado a más de 230.000 trabajadores. Por el tamaño de las empresas implicadas en descuelgues, la mayor parte de ellas son empresas de menos de 50 trabajadores (de las 1.532 inaplicaciones depositadas hasta el momento en 2014, 1.267 corresponden a empresas de menos de 50 trabajadores, es decir, un 82,70\%); y en lo que la sector de actividad concierne, el grueso de las inaplicaciones se concentran en el sector servicios (de las 1.532 inaplicaciones depositadas hasta el momento en 2014, 1.191 corresponden al sector servicios, es decir, un $77,74 \%$, seguido del industrial y a cierta distancia del de la construcción y el agrario.

En cuanto a la evolución de las inaplicaciones entre 2012 y 2014 hay que destacar que en los seis primeros meses de 2013 se produjeron casi el doble de descuelgues que a lo largo de todo el año 2012 (1.390 inaplicaciones en los seis primeros meses de 2013 frente a los 748 descuelgues de 2012 -desde marzo a diciembre-). La tendencia parece que va a continuar en 2014, si bien de forma más matizada y, aún es pronto para saberlo, con cierto proceso de retroceso. Así, mientras que entre enero y marzo de 2014 el número de inaplicaciones mensuales fue siempre superior a las registradas en dichos meses en 2013, a partir de abril el número de inaplicaciones por mes depositadas en 2014 es inferior al correspondiente al mismo mes de 2013. De seguir así la tendencia probablemente el número de inaplicaciones totales en 2014 sea inferior al de 2013. Tal vez, después de un primer momento de ajuste, propiciado, además, por una situación económica que permitía con cierta facilidad dar cumplimento al presupuesto de hecho del procedimiento de inaplicación, se ha ido produciendo un proceso de trasvase del recurso al mecanismo de descuelgue por la apuesta más general por la negociación del convenio propio. El análisis de los datos a nivel de la Comunidad Autónoma de Andalucía parece confirmar esta hipótesis; así, durante el año 2014 continúa la tendencia de menor número de inaplicaciones acordadas respecto al mes similar del año anterior y, por primera vez, el global de inaplicaciones del año 2014 es menor al del año 2013.

En relación al ámbito funcional del convenio inaplicado, de las inaplicaciones de convenios de 2014 depositadas hasta julio, un $96,8 \%$ del total afectaron a convenios de ámbito superior a la empresa, cifra que, si tomamos como dato las inaplicaciones depositadas hasta septiembre de 2014 , se eleva al $97,0 \%$ ( 1.651 de un total de 1.703). Comparada la situación con lo acontecido en 2013 , se observa un cierto aumento en el porcentaje de convenios de ámbito superior a la empresa 
inaplicados (de 3,1 puntos porcentuales, pues del $93,9 \%$ se pasa al $97,0 \%$ ), acompañado de una disminución en el porcentaje de convenios de empresa inaplicados (del 5.1\% se pasa al 3,1\%). De mantenerse estos parámetros durante todo 2014 y comparando el descenso en el núméro de convenios inaplicados, resultaría que mientras que el número de convenios de empresa inaplicados experimenta un descenso del 61,72\% entre 2013 y 2014, el de inaplicaciones de convenios de ámbito superior al de empresa sufre un descenso mucho menor, de un $37,11 \%$.

La mayoría de estos descuelgues se produce a resultas de acuerdo entre las partes (2.279 de las 2.512 en $2013 ; 1.501$ de las 1.532 depositadas hasta julio de 2014 , lo que representa un $90,7 \%$ y un $98 \%$, respectivamente del total, de modo que desde el punto de vista formal la intervención de la Comisión Consultiva Nacional de Convenios Colectivos y órganos similares de las CCAA es muy reducido a estos efectos. Un dato de interés a efectos del análisis de la estructura de la negociación y que parece confirmar la tesis anteriormente expuesta de la existencia de un cierto proceso de progresiva sustitución de una inicial inaplicación del convenio de ámbito superior por la constitución de una unidad de negociación de empresa propia, es el siguiente: un porcentaje muy alto de esos acuerdos de inaplicación (el $80,61 \%$ en la Comunidad Autónoma de Andalucía en 2014 -frente a un 78\% en 2013-, pues no se dispone de datos a nivel estatal) son firmados por representaciones ad hoc. Si bien, de entrada, ello viene a indicar que se trata de unidades que carecen de representación legal y, por ende, sin capacidad para negociar convenios estatutarios, algunos indicios orientan a que pueden convertirse en el germen de la aparición de nuevas unidades empresariales: constatación en alguna concreta Comunidad Autónoma (Andalucía) y la constatación de la abundante litigiosidad que en el último año se está produciendo en relación a convenios de empresa negociados por representantes sin legitimidad.

Desde el punto de vista sustancial y en lo relativo al contenido de las inaplicaciones, en su mayor parte comportan pactos de reducción salarial, con lo cual el mecanismo provoca el efecto de la devaluación interna de salarios. En 2013, un 66,6\% de las inaplicaciones afectaron a la cuantía salarial (un 62\% en 2014 teniendo en cuenta las inaplicaciones depositadas hasta julio de 2014) y si a ellas sumamos las relativas a cuantía salarial y sistema de remuneración, el porcentaje se eleva al 77\% (casi idéntico porcentaje se alcanza en $2014-77,2 \%-$, pues si bien el porcentaje de inaplicaciones afectantes a la cuantía salarial fue inferior no ocurrió lo mismo con el correspondiente a cuantía salarial y sistema de remuneración). Un porcentaje importante de inaplicaciones se traduce en cambios en el régimen del tiempo de trabajo, lo que, igualmente, incide en el efecto más amplio de reducción de los costes laborales unitarios (un 3,5\% de inaplicaciones en 2013 y $6,1 \%$ de las depositadas hasta julio de 2014 afectaron a cuantía salarial y jornada de trabajo).

\subsection{LOS EFECTOS INDIRECTOS: LA INCIDENCIA DE LA REFORMA DE LA ESTRUCTURA NEGO- CIAL SOBRE LA CUANTÍA SALARIAL}

Desde el año 2000, la variación salarial media pactada en los convenios de empresa siempre ha sido inferior tanto a la correspondiente a los convenios de ámbito superior como a la total (oscilando la primera entre los años 2000 a 2011 entre el 3,09 y 1,26, mientras que la variación en los convenios de ámbito superior a la empresa fue de un máximo del 3,65\% a un mínimo del 1,5\%). Sólo en el año 2012 (con datos aún provisionales aunque no parece que vaya a cambiar el sentido de la tendencia) el aumento salarial medio pactado en convenios de empresa fue sensiblemente superior tanto al aumento convencional de niveles superiores a la empresa como al general (un $1,21 \%$ frente a un $0,99 \%$ y un $1,01 \%$, respectivamente. 
Jesús Cruz Villalón, Patrocinio Rodríguez Ramos / Primeras valoraciones acerca de los efectos de la reforma laboral de 2012 en materia de estructura de la negociación colectiva en España

Por otro lado, se constata, si bien aún con resultados provisionales (y dejando entre paréntesis el año 2012), la fuerte disminución que los incrementos salariales medios pactados han venido sufriendo en los últimos años, tanto en el negociación colectiva de empresa como en la de ámbito superior; una disminución de 1,59 y 1,45 puntos porcentuales, respectivamente, entre 2011 y 2013. Asimismo destaca la significativa menor cuantía en el incremento salarial medio pactado en 2013 en los convenios de empresa frente a los convenios de ámbito superior $(0,04 \%$ y $0,57 \%$, respectivamente), situación y tendencia que parece no van a mantenerse en 2014 , donde los aún muy provisiones datos muestran incrementos salariales medios pactados muy próximos en ambos niveles de negociación $(0,48 \%$ y $0,56 \%$, respectivamente). Parece, pues, que va a consolidarse esa tendencia ya puesta de manifiesto en los primeros análisis de la reforma de 2012, de significativa convergencia en el incremento salarial pactado en convenios de empresa y de ámbito superior. Es decir, el cambio en la estructura parece que ha conducido a cierta irrelevancia del nivel de negociación, de empresa o superior, a la hora de fijar la cuantía salarial.

Ahora bien, con ser esto así en términos de resultado final no cabría desconocer dos datos importantes. En el primer año de vigencia de la reforma, 2013, de fuerte impacto de la misma, el incremento salarial medio pactado en los convenios de empresa fue sensiblemente inferior al pactado en los convenios de ámbito superior, lo que podría evidenciar que la preferencia aplicativa del convenio de empresa produjo una cierta devaluación salarial en dicho nivel. De otro lado, en conexión y concordancia con lo anterior, la presión indirecta que la regla de la preferencia aplicativa de los convenios de empresa puede suponer para los sujetos negociadores de convenios sectoriales podrías estar dando lugar a que en tales niveles los incrementos salariales pactados no sean tan elevados como los que pudieran alcanzarse en una situación de inexistencia de dicha regla de preferencia aplicativa.

La evolución de la variación salarial media una vez considerada la incidencia de las cláusulas de salvaguardia es muy similar al recién comentado discurrir del incremento salarial medio pactado convencionalmente.

En relación a la evolución de las cláusulas de garantía salarial en la negociación colectiva, a partir de 2009 se produce un fuerte descenso en el porcentaje de convenios con cláusula de garantía salarial, tanto a nivel de empresa como en los convenios de ámbito superior (de máximos del $47,3 \%$ y el $65,4 \%$ en el año 2004 en los convenios de empresa y en el año 2005 en los de ámbito superior, respectivamente, se pasa a mínimos del $12,2 \%$ y el $18,8 \%$, si bien con datos provisionales, en el año 2013, en dichos y respectivos niveles). Por otro lado, se observa cómo desde el año 2000, el porcentaje de convenios con cláusulas de garantía salarial ha sido siempre superior en los convenios de ámbito superior al de empresa que en los de ámbito empresarial, siendo tal porcentaje entre los años 2000 a 2008 de, en torno, al $60 \%$ en los convenios de ámbito superior a la empresa y de, en torno, al $45 \%$ en los de ámbito empresarial para descender a un porcentaje medio del $38 \%$ entre los años 2009 a 2013 en los primeros y de un porcentaje medio del $29 \%$ en idéntico período en los segundos. Es decir, la diferencia porcentual entre los convenios con cláusula de garantía salarial en niveles superiores al de la empresa y en niveles empresariales se reduce notablemente en los últimos años, pasando de los aproximadamente 15 puntos porcentuales de diferencia a los 9 puntos porcentuales.

Este descenso generalizado de las cláusulas de garantía salarial pudiera estar reflejando también un paulatino proceso de independencia de la negociación colectiva del referente del IPC a la hora de establecer el régimen salarial, su cuantía y la garantía de ingresos mínimos. 


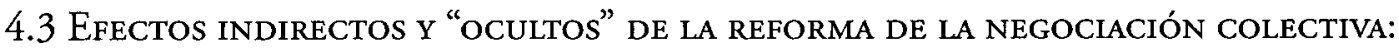 EL DESEQUILIBRIO DE POSICIONES NEGOCIADORAS}

Cuando han transcurridos tres años desde la entrada en vigor de la reforma laboral de 2012, puede tenerse la perspectiva suficiente para valorar el impacto que tal reforma ha tenido sobre las relaciones laborales en su conjunto $y$, muy especialmente, sobre el modelo de negociación colectiva que viene rigiendo desde hace ya varias décadas. Ya desde los primeros análisis de la reforma de 2012 hubo una coincidencia bastante generalizada en valorar que los cambios en materia de negociación colectiva eran los de mayor calado, incluso para algunos con diferencia el que afectaba en mayor medida a la arquitectura general con la que se había construido el sistema de relaciones laborales desde la implantación de la democracia. Por ello, se pensaba que el funcionamiento de la negociación colectiva podría ser la vertiente institucional más afectada del conjunto del sistema de relaciones laborales desde un punto de vista estructural a resultas de la aplicación práctica de tal reforma.

Pasado el tiempo, con un análisis más afinado y de cierta profundidad de lo sucedido, cabe confirmar que la trascendencia de la reforma ha resultado muy intensa, en términos tales que ha provocado una pérdida de la centralidad de la negociación colectiva, que ha perdido fortaleza y capacidad de gestión y condicionamiento de la evolución del mercado de trabajo, provocando un manifiesto debilitamiento del protagonismo de las organizaciones sindicales a través de su menor influencia en los contenidos de los convenios.

Para poder confirmar esta conclusión es obligado advertir que el panorama se ha vuelto mucho más complejo, por una disociación entre determinadas realidades aparentes y otras más subyacentes por encontrarse ocultas. Nos movemos en un juego de espejos, que a veces distorsionan la realidad, al extremo que desde una perspectiva formal podría parecer que sustancialmente el panorama general apenas ha cambiado, cuando si se enfoca la mirada más allá de esos espejos deformadores se advierte el verdadero alcance cualitativo de la mencionada reforma.

No cabe la menor duda de que la reforma laboral se concentra, como hemos comentado, en tres, a lo más en cuatro, aspectos bastante concretos del régimen jurídico del marco de funcionamiento de la negociación colectiva, de modo que podría afirmarse que el cuadro normativo general sustentador del modelo pervive. En efecto, permanecen las reglas básicas relativas a los sujetos legitimados que permite un intenso protagonismo sindical del proceso; a la eficacia general del convenio colectivo que propicia una amplia tasa de cobertura; a la libertad de fijación de ámbitos que da pie a una pervivencia de una amplia red de convenios sectoriales; así como a la amplitud de contenidos negociales que procura que los convenios colectivos asuman un papel central en la determinación de los contenidos negociales.

Sin embargo, al propio tiempo esos tres o cuatro aspectos sobre los que se concentra la reforma de 2012 afectan a órganos vitales del modelo, en términos tales que un simple cambio en tales aspectos logra provocar un decisivo revulsivo en el equilibrio de posiciones de las partes, al extremo que reorienta cualitativamente el devenir de los procesos negociales: pérdida de efectividad de la ultraactividad de los convenios colectivos, procedimiento no consensuado de los descuelgues convencionales, preferencia aplicativa absoluta de los convenios colectivos de empresa, así como limitación relevante en los contenidos negociales.

Para incrementar los riesgos de distorsión de los espejos, cierto tipo de datos estadísticos suministradores de información respecto de los resultados en cuanto a efectos de los mencionados cambios pueden ofrecer una imagen errónea de lo que ha sucedido, por cuanto que los mismos 
Jesús Cruz Villalón, Patrocinio Rodríguez Ramos / Primeras valoraciones acerca de los efectos de la reforma laboral de 2012 en materia de estructura de la negociación colectiva en España

pueden transmitir la idea de que nos enfrentamos a un cambio lampedusiano, en el sentido de que se cambian reglas tradicionales y centrales del sistema, de notable trascendencia desde la perspectiva jurídico formal, pero sin que desde el enfoque material se transforme casi nada la negociación colectiva tal como ha venido funcionando desde que se implantó el actual modelo hace más de tres décadas.

En efecto, frente a la tesis de que el modelo ha provocado un resultado de fuerte desequilibrio entre los protagonistas de las relaciones laborales, se puede aducir que por diversos mecanismos legales, judiciales y negociales se han conservado los precedentes niveles negociales, sin que la ultraactividad haya derivado en la decadencia de un elevado número de unidades negociales, ni se haya reducido la tasa de cobertura; se puede afirmar que la preferencia aplicativa de los convenios de empresa no ha reducido el peso porcentual de los convenios sectoriales y que el incremento en términos absolutos de las nuevas unidades empresariales no ha sido relevante desde el punto de vista del número de trabajadores afectados por los mismos al tratarse de microunidades; se puede alegar que han sido marginales los arbitrajes de descuelgue convencional, pues la práctica totalidad de las inaplicaciones han sido resultado de acuerdos entre las partes y por añadidura con una afectación en términos de porcentaje reducido respecto del total de trabajadores cubiertos por la negociación colectiva; en fin, se puede considerar que las limitaciones a los contenidos negociables no son relevantes, por afectar a aspectos puntuales del habitual clausulado convencional.

Frente a ello, la descripción precedente de lo sucedido muy probablemente se corresponde con las sombras de la alegoría de la caverna de Platón; son proyecciones distorsionadas de la realidad, que impiden detectar la posición real de los personajes y las herramientas con las que se mueven, sin detectar las aguas subterráneas que han cambiado sustancialmente el escenario efectivo en el que se desarrolla hoy en día la negociación colectiva.

Para empezar, no es poco influyente la concepción de conjunto que se tiene de la funcionalidad que ha tenido la negociación colectiva y la actitud con la que se enfrenta el legislador a su reforma. Basta hacer una lectura de conjunto de las medidas adoptadas para percibir en todas ellas un hilo conductor común de fuerte desconfianza frente a la negociación colectiva. La idea subyacente no es otra que para el legislador de la reforma una negociación colectiva potente produce efectos negativos sobre la evolución de la economía y, en particular, provoca consecuencias dañinas para la competitividad y, por ende, para el empleo. A partir de ahí se comprende que todas las medidas van dirigidas a debilitar la posición sindical en el desarrollo de la negociación colectiva: pérdida de impacto de la ultraactividad, búsqueda del descuelgue convencional al margen de los propios procesos negociales, desapoderamiento a los interlocutores sociales para que diseñen la estructura de la negociación colectiva, así como fijación de topes máximos o de prohibiciones a la libre decisión de las partes de decidir acerca de los contenidos negociables que desean tratar en la mesa de negociación.

De otro lado, lo relevante para apreciar los efectos materiales de la reforma en materia de negociación colectiva no es tanto la identificación de los resultados inmediatos externos o aparentes, que pueden ser menores, cuanto la constatación del logro de los objetivos finales en el equilibrio de posiciones de las partes, que muestran el impacto real de depreciación y debilitamiento de la negociación colectiva. 